\title{
Comparison of a homemade blood culture broth containing a papain digest of liver, with four commercially available media for the isolation of anaerobes from simulated paediatric blood cultures
}

\author{
GH HUNT, ELIZABETH H PRICE \\ From the Department of Clinical Microbiology, Queen Elizabeth Hospital for Children, Hackney Road, \\ London, E2 8PS
}

SUMMARY The recovery of small inocula of fastidious organisms, mainly non-sporing anaerobes, $\stackrel{\vec{N}}{\vec{N}}$ was studied in simulated paediatric blood culture experiments where only $1.5 \mathrm{ml}$ of blood was 9 added to each broth. A $25 \mathrm{ml}$ homemade Queen Elizabeth Hospital medium (QEH medium) $\overrightarrow{0}$ containing a papain digest of liver showed the best overall performance during the first four days $\stackrel{\$}{\circ}$ of incubation; this medium was also satisfactory for maintenance of the majority of the organisms $\frac{0}{0}$ tested for longer than one week. LAB M Fastidious Anaerobe Broth (75 ml) with thymidine, also showed early isolation and satisfactory survival of most organisms. Difco Thiol broth, $50 \mathrm{ml}$ with $\vec{\varnothing}$ Liquoid, yielded early growth of the three strains of Bacteroides fragilis tested and maintained! these organisms well; however, variable results were obtained with some other organisms Difco Thiol media. Southern Group Brewer's thioglycollate broth $(80 \mathrm{ml})$ gave the least satisfaetory performance.

Blood cultures in children present special problems as often only a small amount of blood is obtained and the total number of viable organisms added to each medium may be low. Not uncommonly, only one blood culture broth is inoculated because of difficulty in obtaining blood from a small, sick infant. Even so it is important that fastidious pathogens including anaerobes, should be isolated as rapidly as possible. Ideally, any blood culture medium used in paediatric practice should be able to produce rapid growth of small inocula of most potential pathogens.

The main purpose of the present work was to compare the performance of a homemade Queen Elizabeth Hospital medium (QEH medium) already in use in this paediatric hospital in $25 \mathrm{ml}$ volumes, with commercial media in the volumes at which they are usually available. The QEH medium was also tested at a larger volume $(50 \mathrm{ml})$ to see if this had any effect on the recovery of organisms. Only $1.5 \mathrm{ml}$ of blood was added to each bottle as this represents the average amount of blood being added to blood $\overrightarrow{\overrightarrow{0}}$ cultures in this paediatric hospital. The organisms tested were primarily non-sporing anaerobes including three strains of Bacteroides fragilis. The experiment was also extended to include some relatively용 fastidious aerobic organisms and also some aerobes: with particular relevance for paediatric practice.

The basis of QEH medium is a combination of sodium thioglycollate, and "Panmede", a papain digest of ox liver (obtainable from Paines \& Byrne, 을 Greenford, Middlesex) which has been used as a $>$ growth promoting nutrient for isolation of을. Legionella pneumophila, ${ }^{1}$ Trichomonas vaginalis, ${ }^{2} \bar{N}$ Entamoeba invadens, ${ }^{3}$ Mycoplasma, ${ }^{4}$ and Candida ${ }^{2}$. species. Trisodium citrate has also been added ${ }^{N}$ routinely for some years for its anticoagulant effect ${ }_{\omega}^{N}$ and this is particularly necessary where larger vol- 0 umes of blood, such as $5.0 \mathrm{ml}$, are added to the 250 $\mathrm{ml}$ broth. Certain authorities consider citrate to be $\bar{\varnothing}$ inhibitory to the growth of some organisms ${ }^{56}$ and? the medium was therefore tested with and without 7 added citrate. Glucose, $0.5 \%$, was added to the medium in order to produce more rapid growth of organisms utilising it. 


\section{Material and methods}

\section{BLOOD CULTURE MEDIA}

The homemade QEH medium was made up according to the following formula:

$\begin{array}{lr}\text { "Panmede" } & 2.5 \mathrm{~g} \\ \text { Glucose } & 0.5 \mathrm{~g} \\ \text { Sodium chloride } & 0.5 \mathrm{~g} \\ \text { Tri-sodium citrate } & 0.6 \mathrm{~g} \\ \text { Sodium thioglycollate } & 0.1 \mathrm{~g} \\ \text { Agar } & 0.1 \mathrm{~g} \\ \text { Distilled water } & 100 \mathrm{ml}\end{array}$

It was dispensed in $25 \mathrm{ml}$ or $50 \mathrm{ml}$ quantities in $2 \mathrm{oz}$ $(56 \mathrm{~g})$ medical flat bottles with a perforated metal screw cap and a penetrable rubber liner. The final $\mathrm{pH}$ was adjusted to 7.3 and the bottles were autoclaved at $10 \mathrm{lb}(4.5 \mathrm{~kg})$ for $15 \mathrm{~min}$ with loosened caps which were secured tightly as soon as they were removed from the autoclave.

The media tested were as follows:

(i) QEH medium $(25 \mathrm{ml})$.

(ii) QEH medium $(50 \mathrm{ml})$.

(iii) $\mathrm{QEH}$ medium $(50 \mathrm{ml})$ without citrate but otherwise made up according to the above formula.

(iv) Fastidious Anaerobe Broth (FAB) $(75 \mathrm{ml})$ with thymidine, (LAB M, LAB 71) carbon dioxide flushed under reduced pressure.

(v) Brewer's thioglycollate broth $(80 \mathrm{ml})$ (Southern Group Laboratories, 0586C).

(vi) Thiol broth (Difco 0355/30) (50 ml) under vacuum and with added carbon dioxide, prepared by the manufacturers.

(vii) Thiol broth (Difco 1723/30) $(50 \mathrm{ml})$ under vacuum and with added carbon dioxide and sodium polyanethol sulphonate (Liquoid), prepared by the manufacturers.

Two strains of Bacteroides fragilis isolated from clinical specimens were also tested in the following medium:

(viii) QEH medium $(25 \mathrm{ml})$ without citrate but otherwise made up according to the above formula.

The media used were all fresh; the laboratoryprepared media were two weeks old or less and the commercial media were used within two weeks of purchase. Media were tested in triplicate.

BLOOD

Defibrinated horse blood (Gibco Europe Limited) $(1.5 \mathrm{ml})$ was added to each bottle.

\section{ORGANISMS}

The following organisms were tested:
Anaerobes

Bacteroides fragilis NCTC 9344

Bacteroides fragilis 2 clinical isolates

Bacteroides melaninogenicus NCTC 9336

Fusobacterium polymorphum NCTC 10562

Bacteroides corrodens NCTC 10596

Veillonella Hare group V NCTC 9805

Veillonella sp clinical isolate

Anaerobic Coccus group 1 (Peptococcus) NCTC 9801

$\left.\begin{array}{l}\text { Peptostreptococcus prevotii } \\ \text { Peptostreptococcus anaerobius }\end{array}\right\} \begin{aligned} & \text { provided by the } \\ & \text { Public Health } \\ & \text { Laboratory, } \\ & \text { Luton. }\end{aligned}$

Eubacterium sp clinical isolate

Aerobes

Streptococcus sanguis clinical isolate.

Haemophilus influenzae Pittman type b. clinical isolate.

Beta haemolytic Streptococcus. Lancefield group B. clinical isolate.

Salmonella virchow clinical isolate.

Listeria monocytogenes clinical isolate.

Staph aureus thymidine-dependent. clinical isolate.

Neisseria meningitidis group B. clinical isolate.

Streptococcus mitior, pyridoxal-dependent ref R80/2345; provided by the Public Health Laboratory, Colindale, London.

None of the organisms isolated from clinical specimens had ever been grown in any of the blood culture broths tested.

INOCULUM

Each organism was grown in Robertson's cooked meat medium overnight and tenfold dilutions were made in sterile distilled water. From each dilution, $0.1 \mathrm{ml}$ was added to $2 \mathrm{ml}$ sterile glycerol/Lemco broth (10\% glycerol and $1.0 \%$ Lab-Lemco from Oxoid). Each dilution was well mixed and $0.1 \mathrm{ml}$ was transferred to a blood agar plate or appropriate medium for a surface colony count. The glycerol broth dilutions were then stored at $-70^{\circ} \mathrm{C}$ and the appropriate dilution was selected for the experiment according to the results of the colony counts.

This storage method made possible the addition of very small inocula of most test organisms, often less than 10 colony forming units (CFU) per bottle. This provided a more severe test for the media than would have been given by larger inocula. However, it is important to remember that where small inocula are tested, there is a possibility that some bottles will not have any viable organisms added to them. There was a minimum inoculum level below which growth did not occur in any medium. This was shown with Bacteroides melaninogenicus which required a 
minimum challenge of $10 \mathrm{CFU} /$ bottle before growth was obtained. Two experiments with 6 and 3 CFU added per bottle failed to produce growth in any of the bottles tested.

The fact that dilution in a glycerol broth overcomes the lethal effect of freezing for some organisms has been previously described. ${ }^{7-9}$ The only anaerobe which did not survive freezing was the Eubacterium species. Some of the fastidious aerobic organisms did not survive the process and dilutions were then made and stored at $4^{\circ} \mathrm{C}$. Neisseria meningitidis did not tolerate $4^{\circ} \mathrm{C}$ and manipulations with this organism were made at room temperature.

\section{METHOD OF INOCULATION}

The relevant glycerol/Lemco storage broth was thawed and the required volume to give a small inoculum of the test organisms was calculated and added to $50 \mathrm{ml}$ fresh defibrinated horse blood, and thoroughly mixed. $1.5 \mathrm{ml}$ of the horse blood was inoculated into each bottle with a disposable needle and syringe. Three bottles were tested for each blood culture medium. To assess the number of viable organisms inoculated, a colony count was made from the infected horse blood. A $0 \cdot 1 \mathrm{ml}$ amount was spread on the plate for a surface colony count and also $0.5 \mathrm{ml}$ and $1.0 \mathrm{ml}$ were added to a suitable melted medium and a pour plate was made.

\section{METHOD OF SUBCULTURE}

Subcultures for all media except Difco Thiol broth, were made by removing the caps and sampling with a $12.5 \mu$ l disposable plastic loop. The Difco Thiol broths were sampled with a syringe and needle and $0.25 \mathrm{ml}$ was removed into a sterile bijou bottle and the loop sample taken directly from the bijou bottle. In a pilot trial, all the other media were subcultured by syringe and needle without removing the cap, as described for the Difco media. The growth from these bottles was compared with growth obtained by direct sampling with a loop. No difference was found in the amount of growth by the two methods. The organisms investigated in this pilot trial included, Bacteroides fragilis (two clinical isolates), Peptostreptococcus prevotii, Peptostreptococcus anaerobius, Bacteroides corrodens, Clostridium novyii, Eubacterium species, and Neisseria meningitidis.

Table 1 Comparison of media for growth of 12 anaerobes, percentage of bottles showing growth out of total number of bottles inoculated

\begin{tabular}{|c|c|c|c|c|c|c|c|c|}
\hline \multirow[t]{2}{*}{ Medium } & \multicolumn{8}{|c|}{ Day of subculture } \\
\hline & 1 & 2 & 3 & 4 & 6 & 7 & 14 & 30 \\
\hline $\begin{array}{l}\text { QEH medium }(25 \mathrm{ml}) \\
\text { QEH medium }(50 \mathrm{ml}) \\
\text { QEH medium }(50 \mathrm{ml}) \text { (no citrate) } \\
\text { FAB }(75 \mathrm{ml}) \\
\text { Southern Group Brewer's } \\
\text { thioglycollate }(80 \mathrm{ml})\end{array}$ & $\begin{array}{l}78.0 \\
50.0 \\
58.5 \\
56.0 \\
17.0\end{array}$ & $\begin{array}{l}86.0 \\
69.5 \\
83.5 \\
80.5 \\
50.0\end{array}$ & $\begin{array}{l}92.0 \\
75.0 \\
83.5 \\
80.5 \\
65.5\end{array}$ & $\begin{array}{l}94.5 \\
80.5 \\
72.0 \\
89.0 \\
69.5\end{array}$ & $\begin{array}{l}94.5 \\
64.0 \\
66.5 \\
97.0 \\
56.0\end{array}$ & $\begin{array}{l}86.0 \\
61.0 \\
66.5 \\
94.5 \\
50 \cdot 0\end{array}$ & $\begin{array}{l}78.0 \\
47.0 \\
58.5 \\
92.0 \\
44.5\end{array}$ & $\begin{array}{l}72 \cdot 0 \\
39 \cdot 0 \\
47 \cdot 0 \\
72 \cdot 0 \\
31 \cdot 0\end{array}$ \\
\hline $\begin{array}{l}\text { Difco Thiol ( } 50 \mathrm{ml}) \\
\text { Difco Thiol + Liquoid }(50 \mathrm{ml})\end{array}$ & $\begin{array}{l}36 \cdot 0 \\
47 \cdot 0\end{array}$ & $\begin{array}{l}58 \cdot 5 \\
69 \cdot 5\end{array}$ & $\begin{array}{l}61 \cdot 0 \\
72 \cdot 0\end{array}$ & $\begin{array}{l}69 \cdot 5 \\
72 \cdot 0\end{array}$ & $\begin{array}{l}78 \cdot 0 \\
78 \cdot 0\end{array}$ & $\begin{array}{l}78 \cdot 0 \\
75 \cdot 0\end{array}$ & $\begin{array}{l}66 \cdot 5 \\
66 \cdot 5\end{array}$ & $\begin{array}{l}50 \cdot 0 \\
56 \cdot 0\end{array}$ \\
\hline
\end{tabular}

For further details of the growth of the 12 anaerobes and numbers of bottles tested for the different media, see Tables $2,3,4$ and the text.

Table 2 Bacteroides fragilis No of blood culture bottles showing growth; each organism added to 3 bottles of each medium

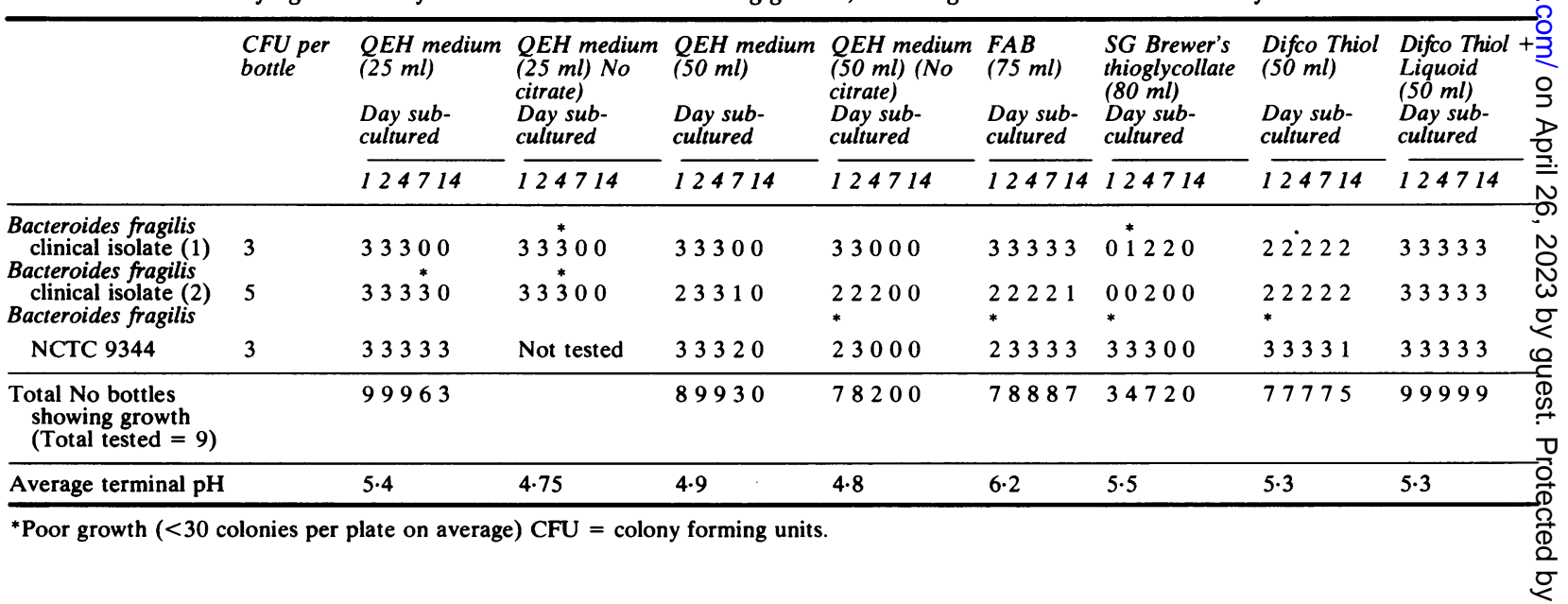


Table 3 Anaerobes other than Bacteroides fragilis No of blood culture bottles showing growth; each organism added to 3 bottles of each medium

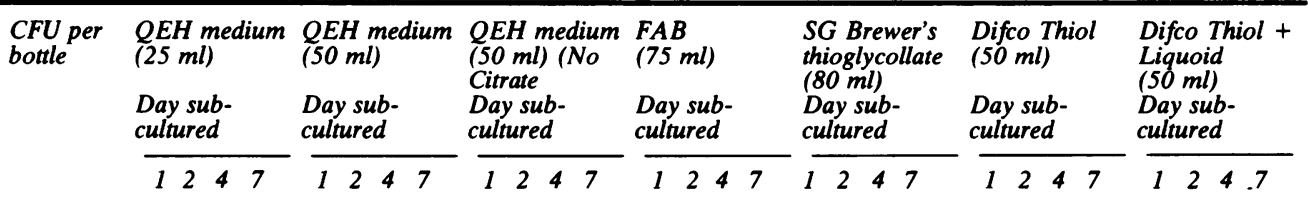

Gram-negative anaerobic bacilli

(1) Bacteroides melaninogenicus

NCTC 9336
(2) Fusobacterium polymorphum NCTC 10562

(3) Bacteroides corrodens

* NCTC 10596

Gram-negative anaerobic cocci

(1) Veillonella Hare gp V NCTC 9805

(2) Veillonella sp clinical isolate

Gram-positive anaerobic cocci

(1) Anaerobic coccus gp I 13 NCTC 9801

(2) Peptostreptococcus anaerobius 7

(3) Peptostreptococcus prevotii

Gram-positive anaerobic bacilli

Eubacterium sp clinical isolate 8

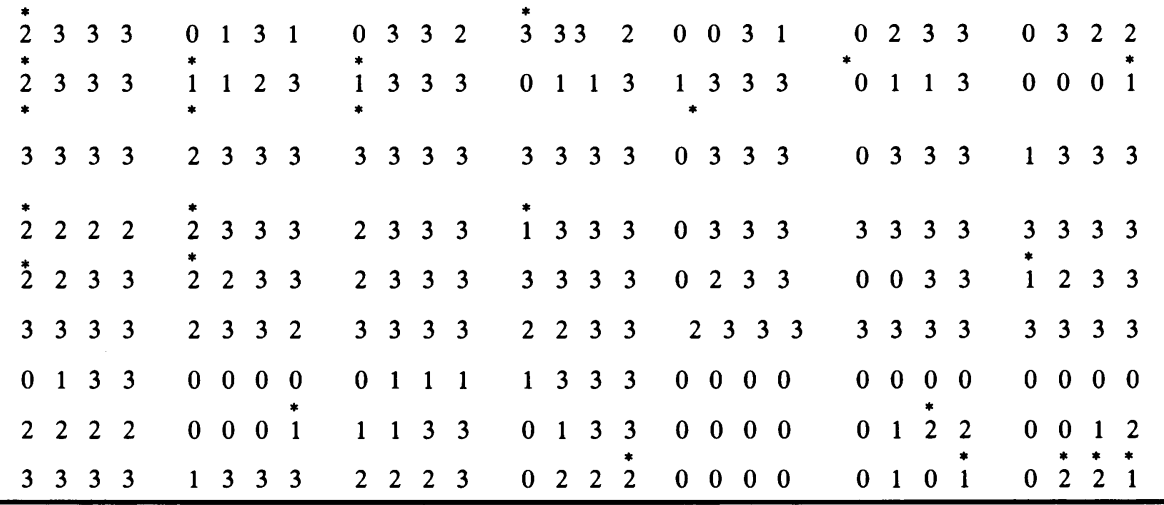

Table 4 All anaerobes tested including B fragilis. Total No of blood culture bottles showing growth out of 36 bottles inoculated for each medium

$\begin{array}{lllllllll}28313431 & 18252922 & 21302624 & 20293234 & 6182518 & 13212528 & 17252627\end{array}$

* Poor growth ( $<30$ colonies per plate on average) CFU $=$ colony forming units.

The subcultures were made on blood agar plates not more than 48 hours old. Each bottle was subcultured daily for the first week, then on day 14 , and day 30 and at the end of each experiment a terminal $\mathrm{pH}$ measurement was taken. For the pyridoxaldependent Streptococcus mitior, the blood agar plates were enriched with vitamin $B_{6}$ supplement.

\section{ANAEROBIC SUB-CULTURES}

The blood agar plates used were not prereduced. They were incubated in a Don Whitley 10 litre stainless steel anaerobe jar, with two sachets of catalyst (total amount of catalyst $\mathbf{8} \mathbf{g}$ ). The jar was evacuated by vacuum pump and this was recorded on a manometer. The vacuum was replaced with $10 \%$ carbon dioxide in hydrogen until equilibrium was reached. The jar was left connected to the manometer until a secondary vacuum of $20 \mathrm{~mm}$ mercury was obtained, showing evidence that the catalyst was working. The secondary vacuum was also replaced with $10 \%$ carbon dioxide in hydrogen. Pseudomonas aeruginosa and Clostridium novyii were used as controls. Plates were kept under these conditions for 2-5 days. They were examined daily to detect growth at the earliest possible moment and they were replaced immediately in the anaerobe jar after examination.

\section{Results}

\section{COMPARISON OF THE QEH MEDIUM WITH THE} COMMERCIAL MEDIA

\section{Anaerobes}

The QEH medium $(25 \mathrm{ml})$ had the highest isolation rate of anaerobes from the first to the fourth day of subculture, of any medium tested (Tables $1-4)$. Survival of the anaerobes on the seventh and fourteenth day of subculture was best in Fastidious Anaerobe Broth (FAB) followed by QEH medium $(25 \mathrm{ml})$. Isolation of every anaerobe from one or more of the three bottles inoculated was obtained from QEH medium $(25 \mathrm{ml}), \mathrm{QEH}$ medium $(50 \mathrm{ml})$ without citrate and FAB by the second day of subculture, but not from any of the other media tested.

If the three strains of Bacteroides fragilis are considered alone (Table 2), the QEH medium $(25 \mathrm{ml}$ ) and Difco Thiol broth with Liquoid had the highest isolation rate after the first day's subculture; the best medium for maintenance of these organisms after 14 days was Difco Thiol broth with Liquoid, followed by FAB.

Aerobes

The highest isolation rate for aerobes from the first 
Table 5 Comparison of media for growth of 8 aerobes, percentage of bottles showing growth out of total number of bottles inoculated

\begin{tabular}{|c|c|c|c|c|c|c|c|c|}
\hline \multirow[t]{2}{*}{ Medium } & \multicolumn{8}{|c|}{ Day of subculture } \\
\hline & 1 & 2 & 3 & 4 & 6 & 7 & 14 & 30 \\
\hline $\begin{array}{l}\text { QEH medium }(25 \mathrm{ml}) \\
\text { QEH medium }(50 \mathrm{ml}) \\
\text { QEH medium }(50 \mathrm{ml}) \\
(\text { no citrate })\end{array}$ & $\begin{array}{l}96 \\
75 \\
58 \cdot 5\end{array}$ & $\begin{array}{r}100 \\
96 \\
83\end{array}$ & $\begin{array}{r}100 \\
100 \\
75\end{array}$ & $\begin{array}{r}100 \\
100 \\
71\end{array}$ & $\begin{array}{l}91 \cdot 5 \\
75 \\
67\end{array}$ & $\begin{array}{l}87 \cdot 5 \\
75 \\
67\end{array}$ & $\begin{array}{l}71 \\
54 \\
54\end{array}$ & $\begin{array}{l}50 \\
37 \cdot 5 \\
33\end{array}$ \\
\hline $\begin{array}{l}\text { FAB ( } 75 \mathrm{ml}) \\
\text { Southern Group Brewer's } \\
\text { thioglycollate }(80 \mathrm{ml})\end{array}$ & $\begin{array}{l}79 \\
42\end{array}$ & $\begin{array}{l}83 \\
71\end{array}$ & $\begin{array}{l}91 \cdot 5 \\
75\end{array}$ & $\begin{array}{l}91 \cdot 5 \\
71\end{array}$ & $\begin{array}{l}91 \cdot 5 \\
58 \cdot 5\end{array}$ & $\begin{array}{l}91 \cdot 5 \\
58 \cdot 5\end{array}$ & $\begin{array}{l}79 \\
46\end{array}$ & $\begin{array}{l}54 \\
42\end{array}$ \\
\hline $\begin{array}{l}\text { Difco Thiol }(50 \mathrm{ml}) \\
\text { Difco Thiol + Liquoid }(50 \mathrm{ml})\end{array}$ & $\begin{array}{l}75 \\
75\end{array}$ & $\begin{array}{l}79 \\
75\end{array}$ & $\begin{array}{l}79 \\
75\end{array}$ & $\begin{array}{l}79 \\
75\end{array}$ & $\begin{array}{l}79 \\
71\end{array}$ & $\begin{array}{l}71 \\
67\end{array}$ & $\begin{array}{l}67 \\
54\end{array}$ & $\begin{array}{l}30 \\
37 \cdot 5\end{array}$ \\
\hline
\end{tabular}

For further details of the growth of the 8 aerobes and the numbers of bottles tested for the different media, see Table 6 and the text.

Table 6 Aerobes-No of blood culture bottles showing growth; each organism added to 3 bottles of each medium

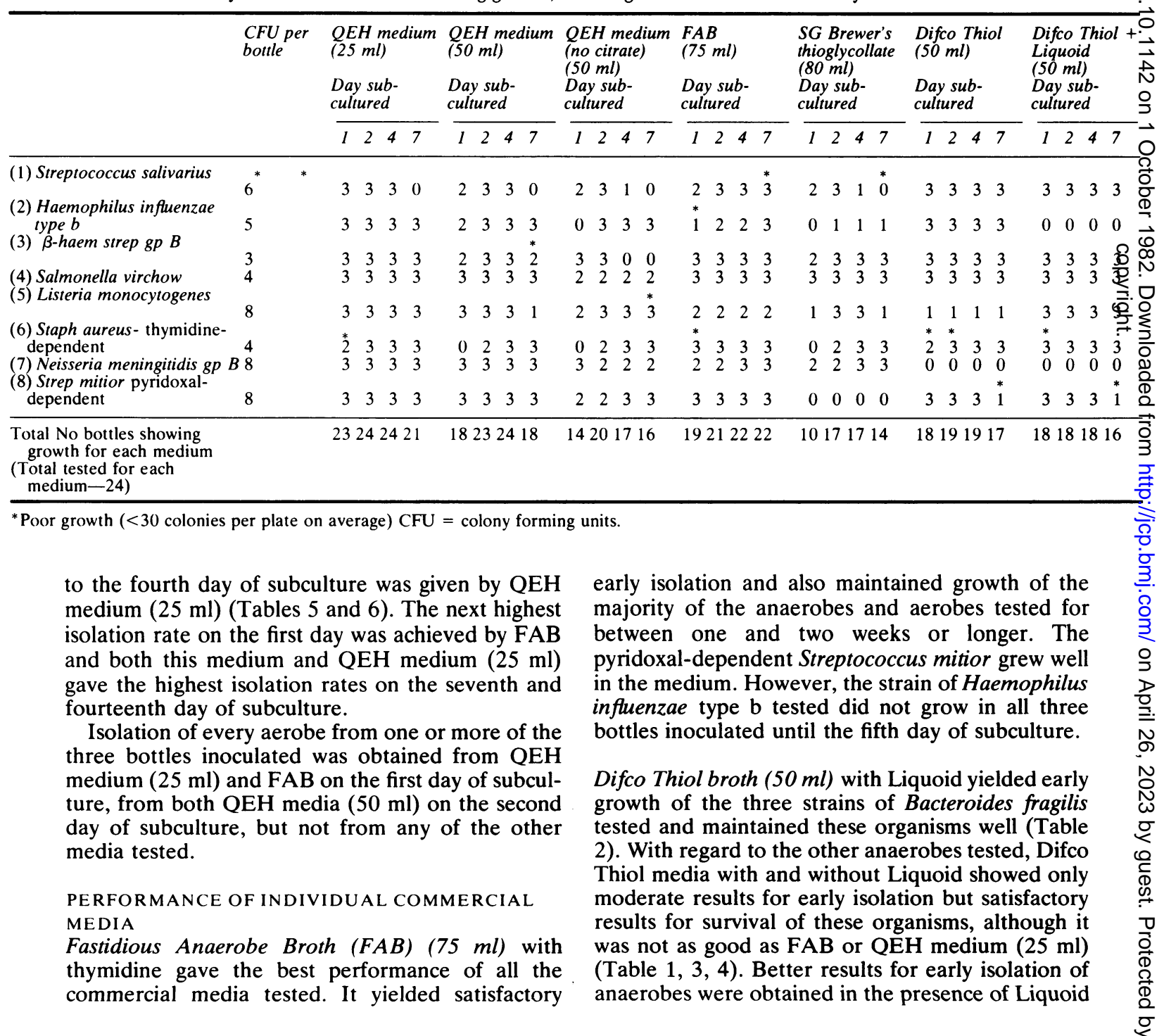


than in its absence in the Difco Thiol media. Neither of the two media grew the Peptostreptococcus anaerobius at any time.

With regard to aerobes, (Table 6) Difco Thiol media both with and without Liquoid, did not yield growth of the Neisseria meningitidis group B strain tested, even when a high inoculum was added in a subsequent experiment; the medium with Liquoid did not grow the strain of Haemophilus influenzae type B tested at any time during the experiment.

Southern Group Brewer's thioglycollate broth ( 80 $\mathrm{ml}$ ) gave the least satisfactory results of any of the media tested for isolation of anaerobes and aerobes on the first, second and seventh day of subculture. Four organisms, Peptostreptococcus prevotii, Peptostreptococcus anaerobius, Eubacterium sp and the pyridoxal-dependent Streptococcus mitior did not grow at all in this medium (Tables 3 and 6).

\section{PERFORMANCE OF THE HOMEMADE MEDIUM}

QEH MEDIUM

The QEH medium $(25 \mathrm{ml})$ gave the best overall performance with regard to early isolation of organisms, both anaerobes and aerobes (Tables 1 and 6). It was also satisfactory for survival of the majority of the organisms tested, although two of the three strains of Bacteroides fragilis did not survive beyond the first week of incubation. In common with FAB, $\mathrm{QEH}$ medium $(25 \mathrm{ml})$ and $\mathrm{QEH}$ medium $(50 \mathrm{ml})$ showed good early growth together with satisfactory survival for at least one week of the pyridoxaldependent Streptococcus mitior in all bottles tested.

Effect of volume The performance of the $25 \mathrm{ml}$ volume of $\mathrm{QEH}$ medium was better for both anaerobes and aerobes than that of the $50 \mathrm{ml}$ volume. The terminal $\mathrm{pH}$ of the $25 \mathrm{ml} \mathrm{QEH}$ medium (with citrate) was slightly higher for 7 of 12 anaerobes and 7 of 8 aerobes, than that of the $50 \mathrm{ml}$ QEH medium (with citrate).

Effect of citrate The QEH medium $(50 \mathrm{ml})$ was tested for all anaerobes and aerobes with and without added citrate. At this volume, there was some inhibition by citrate of the growth of certain anaerobic organisms (Bacteroides melaninogenicus, Fusobacterium polymorphum, Peptostreptococcus prevotii, and Peptostreptococcus anaerobius-see Table 3). However, also at the $50 \mathrm{ml}$ volume, the presence of citrate was associated with a longer survival of the three strains of Bacteroides fragilis tested than was seen in its absence (Table 2). As would be expected, there was a higher terminal $\mathrm{pH}$ in the presence of citrate than in its absence, for nearly all the organisms tested.
The QEH medium $(25 \mathrm{ml})$ was tested with and without added citrate for two strains of Bacteroides fragilis only. As at the $50 \mathrm{ml}$ volume, there was no evidence of citrate inhibition of these organisms at any stage in the experiment and the presence of citrate was associated with improved length of survival in this medium.

\section{Discussion}

The blood culture media were tested in the volumes at which they are usually available and the volume of blood used was related to that commonly added to paediatric blood cultures in this hospital-that is, $1.5 \mathrm{ml}$. The media tested were all fresh as storage of media has been shown to affect the growth of anaerobes. ${ }^{10}$ All the media were designed primarily for isolation of anaerobic organisms and were based on either thioglycollate or Thiol, a thioglycollate type substance. Previous comparisons of such media have given different results. ${ }^{11} 12$

Fastidious Anaerobe Broth $(75 \mathrm{ml})$ with thymidine (FAB), was the most satisfactory commercial medium for use where only small amounts of blood are available, in that it produced good early growth and also sustained the growth of the majority of organisms tested, both anaerobes and aerobes. We confirm the work of Tillotson ${ }^{13}$ which showed that FAB was a satisfactory medium for the growth of pyridoxal-dependent Streptococcus mitior.

Difco Thiol broth has been previously recommended for the isolation of anaerobes. ${ }^{11} 12$ This medium with Liquoid was satisfactory for isolation and survival of Bacteroides fragilis in our study, but its overall results for anaerobic organisms were not as good as some of the other media. One anaerobe, Peptostreptococcus anaerobius did not grow at any time in Difco Thiol broth, both with and without added Liquoid. The failure to grow in media containing Liquoid has been previously described for this organism and some other anaerobic cocci. ${ }^{14-16}$ However, failure to grow could also be related to the low test inoculum used, in that some bottles may not have had any viable organisms added to them.

For aerobes, Difco Thiol broth, with and without Liquoid, did not yield growth of the Neisseria meningitidis group B strain tested, even when a high inoculum was subsequently added. This medium with added Liquoid did not grow the Haemophilus influenzae type $b$ strain tested at any time and although the low inoculum may again have been a factor, other workers have also shown poor recovery of Haemophilus infuenzae from Difco Thiol broth with Liquoid. ${ }^{17}$ Both of these aerobes are important paediatric pathogens. As there may be only a small amount of blood obtainable for culture from a sick 
infant, it would be valuable if anaerobic culture media used in paediatric practice were able to yield growth of aerobic pathogens (many of which will also be facultative anaerobes).

Southern Group Brewer's thioglycollate medium $(80 \mathrm{ml})$ was previously reported to give good recovery of anaerobes when $5.0 \mathrm{ml}$ of human blood was added. ${ }^{15}$ This medium was unsatisfactory in our hands for simulated paediatric blood cultures where small volumes of defibrinated horse blood were added.

The homemade medium, QEH medium in $25 \mathrm{ml}$ volumes, showed the best overall results of any medium tested for early isolation of the organisms. It was satisfactory for culture of small volumes of blood for anaerobic organisms, but regular subculture is advisable to detect rapid, early growth of organisms. Two of the Bacteroides fragilis strains tested did not survive beyond the first week of incubation. However, as growth of Bacteroiaes: fragilis may not produce visual turbidity, regular subculture of any blood culture medium for this organism would be advisable.

The liver digest, "Panmede", provided sufficient nutrients for the growth of a number of fastidious organisms, including anaerobes. One possible disadvantage of this digest is the resulting deep brown colour of the medium, which may make macroscopic detection of early growth difficult for the inexperienced worker. However, familiarity with the medium and regular subculture would overcome this problem. In common with some other media made from organic material, occasional dead bacteria may be present and could possibly cause confusion in the Gram stain examination. Further processing of the medium would probably remove these organisms.

For QEH medium, the $25 \mathrm{ml}$ volume consistently showed better results than the $50 \mathrm{ml}$ volume. This could have been related to the higher concentration of blood nutrients in the $25 \mathrm{ml}$ volume or to the greater buffering effect of the blood in this lower volume. For all blood culture media, the ratio of volume of blood to volume of broth is an important factor with regard to growth of organisms. ${ }^{15}{ }^{18}$ In this experiment, although the volume of blood added to each medium was the same, the media themselves were not all of the same volume. Higher volumes of blood than are easily available in paediatric practice may be necessary to produce satisfactory results in some commercial media.

In spite of the presence of citrate in QEH medium $(25 \mathrm{ml})$, growth and survival of the majority of organisms tested was very good. At the $50 \mathrm{ml}$ volume of this medium, although citrate was slightly inhibitory to some organisms, Bacteroides fragilis survived longer in the bottles containing citrate, possibly because it prevented a fall in $\mathrm{pH}$ due to the acid products of bacterial metabolism. All the QEH $\vec{\sigma}$ media contained $0.5 \%$ glucose, which is a relatively high concentration of glucose compared with that $\stackrel{\vec{F}}{\vec{m}}$ used in some other blood culture media. The glucose $\overline{0}$ was added to promote rapid growth of organisms $\frac{C}{0}$ utilising it. The metabolism of these organisms $\frac{\bar{\sigma}}{\bar{\omega}}$ would result in the production of acid which could $\vec{\nabla}$ kill them in the absence of a buffer, such as citrate. (Waterworth ${ }^{19}$ described the lethal effect of the fer- ${ }^{\circ}$ mentation of glucose on a number of organisms in $\overrightarrow{0}$ tryptone-soya broth).

Liquoid, sodium polyanethol sulphonate, is often $\vec{\omega}$ recommended as an addition to blood cultures ${ }^{2021}$ 응 for its anticoagulant effect and for its ability to $\dot{\omega}$ inhibit the antibacterial action of fresh blood. How- or ever, some workers do not consider it to be a useful $\vec{\circ}$ addition to paediatric blood cultures. ${ }^{22}$. It was not $\overrightarrow{\vec{A}}$ used in any of the QEH media.

The use of horse blood rather than human blood 0 may have introduced some variable factors into the experiment, as compared with the clinical situation. 0 However, horse blood has also been used by other workers in blood culture experiments. ${ }^{23}$

It was possible to use very small inocula of most anaerobes in the experiment with reasonable accur $\stackrel{\oplus}{\oplus}$ racy by a method involving freezing organisms in ? glycerol/Lemco storage medium. There is a minim inoculum level below which growth will not occur any medium and this has been previously described. ${ }^{23}$ One disadvantage of this method as compared with the clinical situation is that the $\stackrel{\mathbb{Q}}{\unrhd}$ organisms are not in the logarithmic phase of growth $\vec{\overrightarrow{ }}$ when added to the media. However, other workers 3 found no difference in growth of Haemophilus influenzae and a number of anaerobic organisms, in blood culture media inoculated with cultures obtained from frozen vials or grown in broth. ${ }^{17} 24$

Difco Thiol broth is able to inactivate certain $\frac{5}{3}$ antibiotics. ${ }^{12}$. This property is shared by the liver extract "Panmede" and may be an advantage if $\frac{3}{3}$ patients have already started antibiotic therapy before blood cultures are taken. Further details of this will be presented elsewhere.

This work was supported by a grant from the Queen $N$ Elizabeth Hospital for Children Research Appeal $N$ Trust. We should like to thank Miss L Gould and Mr $P$ Salter for valuable technical assistance and Mrs $C \omega$ Kitt for her help in the preparation of the manuscript.

\section{References}

${ }^{1}$ Macrae AD, Greaves PW, Platts P. Isolation of Legionella pneumophila from blood cultures. Br Med J 1979; ;i: 1189.

${ }^{2}$ Feinberg JG, Whittington MJ. A culture medium for $\frac{\mathcal{Q}}{\Phi}$ 
Trichomonas vaginalis donné and species of Candida. J Clin Pathol 1956;10:327-9.

${ }^{3}$ McConnachie EW. A medium for the axenic cultivation of Entamoeba invadens. Nature 1962;194:603-4.

4 Buttery SH. A growth medium for Mycoplasmas and its modification for longer survival of $M$ mycoides in cultures. Bull Epizoot Dis Afr 1967;15:227-30.

${ }^{s}$ Rosner R. Effect of various anticoagulants and no anticoagulant on ability to isolate bacteria directly from parallel clinical blood specimens. Am J Clin Pathol 1968;49:216-9.

- Ellner PD, Stoessel CJ. The role of temperature and anticoagulant on the in vitro survival of bacteria in blood. J Infect Dis 1966;116:238-42.

' Hollander DH, Nell EE. Improved preservation of Treponema pallidum and other bacteria by freezing with glycerol. Appl Microbiol 1954;2:164-70.

${ }^{8}$ Drasar BS, Shiner M, McLeod GM. Studies on the intestinal flora I. The bacterial flora of the gastrointestinal tract in healthy and achlorhydric persons. Gastroenterology 1969;56:71-9.

${ }^{9}$ Crowther JS. Transport and storage of faeces for bacteriological examination. J Appl Bacteriol 1971;34:477-83.

${ }^{10}$ Barr JG. A cooked meat blood culture medium; shelf life and clinical evaluation compared with other systems. $J$ Infect 1980;2:247-58.

"Shanson DC, Barnicoat M. An experimental comparison of Thiol broth with Brewer's thioglycollate for anaerobic blood cultures. J Clin Pathol 1975;28:407-9.

${ }^{12}$ Szawatkowski MV. A comparison of three readily available types of anaerobic blood culture media. Med Lab Sci 1976;33:5-12.

${ }^{13}$ Tillotson GS. Evaluation of ten commercial blood culture systems to isolate a pyridoxal-dependent streptococcus. J Clin Pathol 1981;34:930-4.
${ }^{14}$ Hoare ED. Suitability of "Liquoid" for use in blood culture media with particular reference to anaerobic streptococci. $J$ Pathol Bacteriol 1938;48:573-7.

15 Shanson DC. An experimental assessment of different anaerobic blood culture methods. J Clin Pathol 1974;27:273-9.

${ }^{16}$ Kocka FE, Arthur EJ, Searcy RL. Comparative effects of two sufphated polyanions used in blood culture on anaerobic cocci. Am J Clin Pathol 1974;61:25-7.

${ }^{17}$ Schell RF, Le Frock JL, Babu JP, Robinson DB. Recovery of Haemophilus infuenzae from 23 blood culture media. J Clin Microbiol 1979;9:84-7.

18 Roome APC. Tozer RA. Effect of dilution on the growth of bacteria from blood cultures.J Clin Pathol 1968;21:719-21.

19 Waterworth PM. The lethal effect of tryptone soya broth. J Clin Pathol 1972;25:227-8.

${ }^{20}$ Von Haebler T, Miles AA. The action of sodium polyanethol sulphonate (Liquoid) on blood cultures. J Pathol Bacteriol 1938;46:245-52.

${ }^{21}$ Stokes EJ. Blood culture technique. ACP Broadsheet 81, 1974.

${ }^{22}$ Minkus R, Moffet HL. Detection of bacteraemia in children with sodium polyanethol sulfonate: a prospective clinical study. Appl Microbiol 1971;22:805-8.

${ }^{23}$ Collee JG, Duerden BI, Brown R. Recovery of anaerobic bacteria from small inocula: a model for blood culture studies. $J$ Clin Pathol 1977;30:609-14.

${ }^{24}$ Schell RF, Babu JP, Le Frock JL. Evaluation of ten anaerobic blood culture media. Am J Clin Pathol 1979;72:199-203.

Requests for reprints to: Dr EH Price, Consultant Microbiologist, Queen Elizabeth Hospital for Children, Hackney Road, London E2 8PS, England. 